\title{
Seismic response of multi-story structure with multiple tuned mass friction dampers
}

\author{
Alka Y. Pisal · R. S. Jangid
}

Received: 2 July 2013 / Accepted: 27 January 2014/Published online: 21 February 2014

(C) The Author(s) 2014. This article is published with open access at Springerlink.com

\begin{abstract}
The effectiveness of multiple tuned mass friction dampers (MTMFD) for vibration control of structure over a single tuned mass friction damper (STMFD) is investigated. A five story structure supported with MTMFD is considered and the governing differential equations of motion are derived. The response of the structure under four selected earthquake ground motions is obtained by solving the equations of motion numerically using the state space method. The number of damper in MTMFD is varied and the response of five story structure with STMFD is compared with the response of the same structure with MTMFD. A parametric study is also conducted to investigate the effects of important parameters such as number of dampers in MTMFD, damper frequency spacing, mass ratio, tuning ratio and damper slip force. It is found that for a given structural system and level of excitation an optimum value of the parameters (i.e. frequency spacing, tuning ratio and damper slip force) exists at which the peak displacement of structure attains its minimum value. The response time history of the structure with STMFD and MTMFD with respect to their optimum parameters is compared. It is found that the MTMFD is more effective in controlling the response of the structure in comparison with the STMFD having the same mass.
\end{abstract}

Keywords TMFD $\cdot$ MTMFD $\cdot$ Seismic excitation $\cdot$ Mass ratio $\cdot$ Tuning ratio $\cdot$ Frequency spacing $\cdot$ Slip force

\footnotetext{
A. Y. Pisal $(\bowtie) \cdot$ R. S. Jangid

Department of Civil Engineering, Indian Institute of Technology

Bombay, Powai, Mumbai 400 076, India

e-mail: alka.y.pisal@gmail.com; alka.pisal@iitb.ac.in

R. S. Jangid

e-mail: rsjangid@civil.iitb.ac.in
}

\section{Introduction}

The tuned mass damper (TMD) is a most popular and extensively used device to control vibration in civil and mechanical engineering applications ranging from small rotating machinery to tall civil engineering structures. Similar to TMD, friction dampers (FD) were also found to be very efficient, not only for rehabilitation and strengthening of existing structures but also for the design of structures to resist excessive vibrations (Colajanni and Papia 1995; Qu et al. 2001; Mualla and Belev 2002; Pasquin et al. 2004). In the past, some researchers had proposed the use of FD along with TMD. Ricciardelli and Vickery (1999) considered a single degree of freedom (SDOF) system to which a TMD with linear stiffness and dry friction damping was attached. The system was analyzed for harmonic excitation and design criteria for friction TMD system were proposed. Lee et al. (2005) performed a feasibility study of tunable FD and it was shown that proper sizing of the mass and the fulfillment of the damper criteria allows the designer to use benefit of FD and TMD. Gewei and Basu (2010) analyzed dynamic characteristics of SDOF system with single tuned mass friction damper (STMFD), using harmonic and static linearization solution. The study indicated that the STMFD has benefits of both FD as well as TMD, if designed appropriately.

The main disadvantage of a STMFD is its sensitivity of the effectiveness to the error in the natural frequency of the structure. If the design parameters of the TMD are selected wrongly, it may accelerate the vibration of the system instead of attenuating it. To overcome this difficulty, many researchers had proposed the use of multiple tuned mass damper (MTMD) with different dynamic characteristics (Xu and Igusa, 1992; Joshi and Jangid, 1997). It was shown that MTMD is more effective than STMD. Similar to the 
TMD, the STMFD has the same disadvantage that it also performs effectively only in a narrow frequency range. However, the limitation of narrow frequency range can be improved using MTFMD in place of STMFD. Thus, in this study the effectiveness of multiple tuned mass friction damper (MTMFD) over a STMFD for reduction of response of multi-story structure is studied. The specific objectives of the study are summarized as to (1) formulate the equations of motion and develop solution procedure for the response of multi degree of freedom (MDOF) system with MTMFD, under seismic excitations, numerically; (2) investigate the influence of important parameters such as number of dampers in MTMFD, mass ratio, tuning ratio, frequency spacing and damper slip force on the performance of the MTMFD; (3) obtain optimum values of influencing parameters for different mass ratios of the MTMFD, which may find application in the effective design of MTMFD; and (4) to compare the response of MDOF system attached with MTMFD to the response of same system attached with STMFD having same total mass.

\section{Modeling of MDOF system with MTMFD}

The system configuration considered for the study consists of a primary system of five-story structure attached with MTMFD with different dynamic characteristics as shown

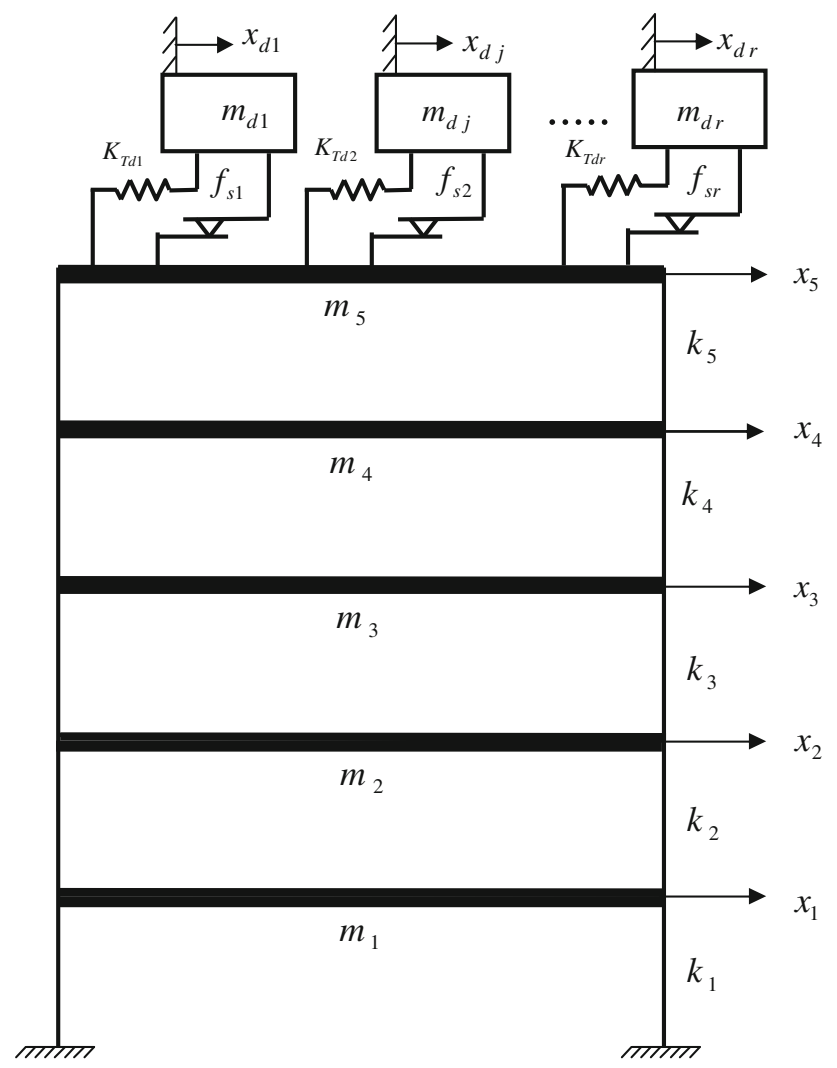

Fig. 1 Five-story structure with MTMFD in Fig. 1. For this study, the following assumptions are made:

1. The structural system of the primary system, i.e., mass and stiffness of each floor are same.

2. Stiffness of each TMFD unit is same.

3. Normalized slip force value of each TMFD unit is kept same.

4. The mass of each TMFD unit is varying. By varying the mass, the natural frequency of each TMFD unit is adjusted to the required value.

5. The natural frequencies of the MTMFD are uniformly distributed around their average natural frequency. It is to be noted that MTMFD with indistinguishable dynamic characteristics are equivalent to a STMFD in which the natural frequency of the individual MTMFD unit is same as that of the equivalent STMFD.

Let $\omega_{\mathrm{T}}$ be the average frequency of all MTMFD and can be expressed as

$\omega_{\mathrm{T}}=\sum_{j=1}^{r} \frac{\omega_{j}}{r}$

where $r$ is the total number of MTMFD, and $\omega_{j}$ is the natural frequency of the $j$ th TMFD is expressed as

$\omega_{j}=\omega_{\mathrm{T}}\left[1+\left(j-\frac{r+1}{2}\right)\right] \frac{\beta}{r-1}$

where $\beta$ is the non-dimensional frequency spacing of the MTMFD, given as

$\beta=\frac{\omega_{r}-\omega_{1}}{\omega_{\mathrm{T}}}$

If $k_{\mathrm{d}}$ is the constant stiffness of each TMFD, then the mass of the $j$ th TMFD is expressed as

$m_{\mathrm{d} j}=\frac{k_{\mathrm{d}}}{\omega_{j}^{2}}$

The ratio of the total MTMFD mass to the total mass of the main structure is defined as the mass ratio and is expressed as

$\mu=\frac{\sum_{j=1}^{r} m_{\mathrm{d} j}}{m_{\mathrm{s}}}$

where $m_{\mathrm{s}}$ denotes the total mass of the primary structure.

The ratio of average frequency of the MTMFD to the fundamental frequency of main structure is defined as tuning ratio, expressed as

$f=\frac{\omega_{\mathrm{T}}}{\omega_{\mathrm{s}}}$

It is to be noted that as the stiffness and normalized damper force of all the TMFD are constant and only mass 
is varying, the friction force adds up. Thus, the nondimensional frequency spacing $\beta$, controls the distribution of the frequency of the TMFD units.

\section{Governing equations of motion and solution procedure}

Let the mass and stiffness of the $i$ th floor of the primary structure is characterized by $m_{i}$ and $k_{i}$, respectively, as shown in Fig. 1. The primary system and each TMFD unit is modeled as SDOF system so that the total degrees of freedom of the combined system configuration considered for the study becomes $r+5$. The governing equations of motion of MDOF system with MTMFD when subjected to earthquake excitations are expressed as

$M \ddot{X}+C \dot{X}+K X=E \ddot{x}_{\mathrm{g}}+B F_{\mathrm{s}}$

$X=\left\{\begin{array}{c}x_{\mathrm{p}} \\ x_{\mathrm{d}}\end{array}\right\}$

where $x_{\mathrm{p}}$ and $x_{\mathrm{d}}$ represent the displacement relative to the ground vector of floors of primary structure and TMFD units of MTMFD, respectively; $M, C$ and $K$ denote the mass, damping and stiffness matrix of the configured system, considered for the study; the matrix $E$ and $B$ are placement matrix for the excitation force and friction force, respectively; $X, \dot{X}$ and $\ddot{X}$ are the relative displacement, velocity and acceleration vectors of configured system, respectively; $\ddot{x}_{\mathrm{g}}$ denotes the ground acceleration, and $F_{\mathrm{s}}$ denotes the vector of friction force provided by the TMFD. These matrices are expressed as

$$
\begin{aligned}
& M=\left[\begin{array}{cc}
M_{\mathrm{p}} & 0 \\
0 & M_{\mathrm{d}}
\end{array}\right] \\
& M_{\mathrm{P}}=\operatorname{diag}\left[m_{1}, m_{2,}, \ldots, m_{5}\right] \\
& M_{\mathrm{d}}=\operatorname{diag}\left[m_{\mathrm{d} 1}, m_{\mathrm{d} 2}, \ldots, m_{\mathrm{d} r}\right]
\end{aligned}
$$

$K=\left[\begin{array}{cccccc}K_{\mathrm{p}}+\sum_{j=1}^{r} K_{\mathrm{d} r} & -K_{\mathrm{d} 1} & -K_{\mathrm{d} 2} & -K_{\mathrm{d} 3} & \ldots & -K_{\mathrm{d} r} \\ -K_{\mathrm{d} 1} & K_{\mathrm{d} 1} & 0 & 0 & \ldots & 0 \\ -K_{\mathrm{d} 2} & 0 & K_{\mathrm{d} 2} & 0 & \cdots & 0 \\ -K_{\mathrm{d} 3} & 0 & 0 & K_{\mathrm{d} 3} & \cdots & 0 \\ \cdot & \cdot & . & \cdot & \cdot & \\ \cdot & . & . & . & . & 0 \\ - & . & . & . & . & \\ -K_{\mathrm{d} r} & 0 & 0 & 0 & 0 & K_{\mathrm{d} r}\end{array}\right]$

$C=\left[\begin{array}{cc}C_{\mathrm{p}} & 0 \\ 0 & 0\end{array}\right]$

where $K_{\mathrm{P}}$ and $C_{\mathrm{p}}$ represent the typical damping and stiffness matrix of dimensions $(5 \times 5)$ of primary structure. It is also to be noted that as the damping matrix of the system is not known explicitly, it is constructed using the Rayleigh's damping considering proportional to mass and stiffness of the main structure as,

$C_{\mathrm{P}}=a_{0} M_{\mathrm{p}}+a_{1} K_{\mathrm{p}}$

where $a_{0}$ and $a_{1}$ are the coefficients which depend on the damping ratio of two vibration mode. For the considered primary structure, damping ratio is taken as $2 \%$ for both the modes of vibration.

$F_{\mathrm{s}}=\left\{\begin{array}{lllll}\sum_{j=1}^{r} F_{\mathrm{s} j} & -F_{\mathrm{s} 1} & -F_{\mathrm{s} 2} & \cdots & -F_{\mathrm{s} r}\end{array}\right\}$

where the friction force of the $j$ th damper is given as

$F_{\mathrm{s} j}=f_{\mathrm{sj}} \operatorname{sgn}\left(\dot{x}_{\mathrm{d} j}-\dot{x}_{5}\right)$

where $\dot{x}_{\mathrm{d} j}$ shows the velocity of $j$ th TMFD and $\dot{x}_{5}$ denotes the velocity of the top story, where MTMFD is attached to the primary structure. The damper forces are calculated using the hysteretic model proposed by Constantinou et al. (1990), using Wen's equation (Wen 1976), which is expressed as,

$F_{\mathrm{s} j}=f_{\mathrm{sj}} Z$

where $f_{\mathrm{s} j}$ is the limiting friction force or slip force of the damper and $Z$ is the non-dimensional hysteretic component which satisfies the following first order non-linear differential equation,

$$
\begin{aligned}
q \frac{\mathrm{d} Z}{\mathrm{~d} t}= & A\left(\dot{x}_{d j}-\dot{x}_{5}\right)-\beta\left|\left(\dot{x}_{d j}-\dot{x}_{5}\right)\right| Z|Z|^{n-1} \\
& -\tau\left(\dot{x}_{d j}-\dot{x}_{5}\right)|Z|^{n}
\end{aligned}
$$

where $q$ represents the yield displacement of frictional force loop, and $A, \beta, \tau$ and $n$ are non-dimensional parameters of the hysteretic loop, which control the shape of the loop. These parameters are selected in such a way that it provides typical Coulomb-friction damping. The recommended values of these parameters are taken as $q=0.0001 \mathrm{~m}, A=1, \beta=0.5, \tau=0.05, n=2$, (Bhaskararao and Jangid 2006). The hysteretic displacement component, $Z$ is bounded by peak values of \pm 1 to account for the conditions of sliding and non-sliding phases.

The limiting friction force or slip force of the damper, $f_{\mathrm{s} j}$ can be expressed in the normalized form by $R_{f}$ as

$R_{f}=\frac{f_{\mathrm{s} j}}{M_{\mathrm{d} j} \cdot g}$

The governing equations of motion are solved using the state space method numerically, since the force deformation behavior of MTMFD is non-linear. 
Table 1 Details of earthquakes considered for Numerical study

\begin{tabular}{|c|c|c|c|c|}
\hline & Recording station & Component & $\begin{array}{l}\text { Duration } \\
(\mathrm{sec})\end{array}$ & $\begin{array}{l}\text { PGA } \\
(\mathrm{g})\end{array}$ \\
\hline $\begin{array}{l}\text { Imperial } \\
\text { Valley } \\
\text { (19 May } \\
1940)\end{array}$ & $\begin{array}{l}\text { El Centro array \# } \\
9\end{array}$ & $\begin{array}{c}\text { I-ELC } \\
180\end{array}$ & 40 & 0.313 \\
\hline $\begin{array}{l}\text { Loma Prieta } \\
\text { (18 October } \\
1989)\end{array}$ & $\begin{array}{l}\text { UCSC } 16 \text { Los } \\
\text { Gatos } \\
\text { Presentation } \\
\text { Centre (LGPC) }\end{array}$ & LGP 000 & 25 & 0.96 \\
\hline $\begin{array}{l}\text { Landers } \\
\text { (28 June } \\
1992)\end{array}$ & Lucerne Valley & LCN 275 & 48.125 & 0.721 \\
\hline $\begin{array}{l}\text { Kobe } \\
\text { (16 January } \\
1995)\end{array}$ & $\begin{array}{l}\text { Japan } \\
\text { Meteorological } \\
\text { Agency (JMA) } \\
99999 \text { KJMA }\end{array}$ & KJM 000 & 48 & 0.82 \\
\hline
\end{tabular}
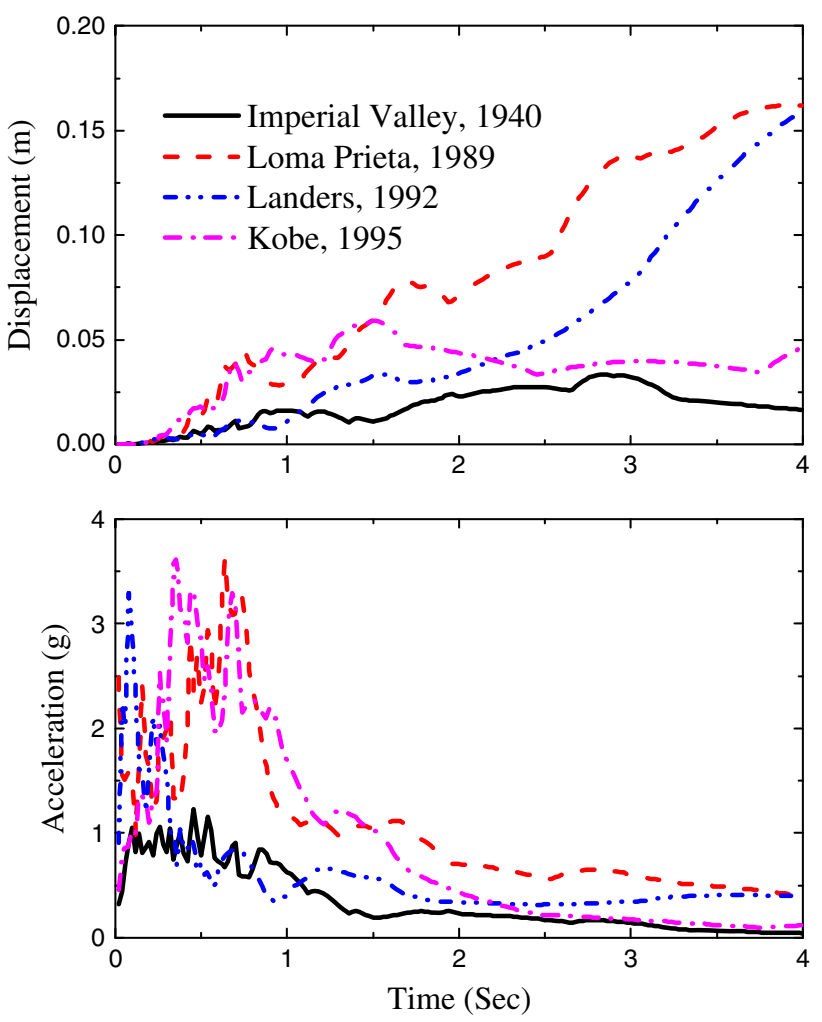

Fig. 2 Displacement and acceleration spectra of four earthquakes considered for the study

\section{Numerical study}

For the numerical study, the five-story structure of fundamental time period of $0.5 \mathrm{~s}$ is considered. The earthquake time histories along with their peak ground acceleration (PGA) and components, which are used for this study are represented in Table 1. The displacement and acceleration

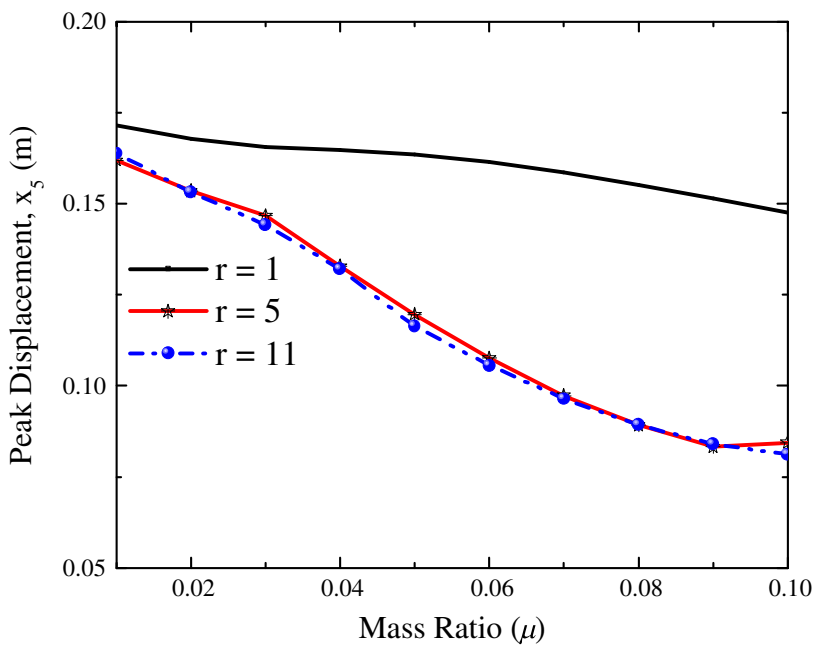

Fig. 3 Variation of peak displacement of top story with mass ratio

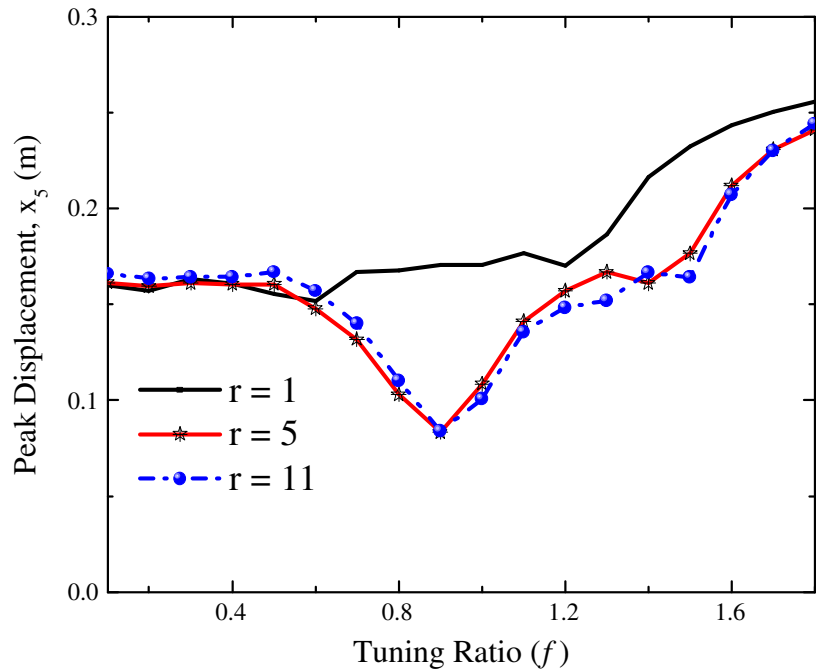

Fig. 4 Variation of peak displacement of top story with tuning ratio

response spectra of the above-mentioned earthquakes are shown in Fig. 2 for $2 \%$ critical damping. The maximum ordinates of acceleration are $1.225,3.616,3.296,3.614 \mathrm{~g}$, occurring at the period of $0.46,0.64,0.08$ and $0.36 \mathrm{~s}$ for Imperial Valley, Loma Prieta, Landers and Kobe earthquakes, respectively. The spectra of these ground motion indicate that these ground motions are recorded on a rocky site or on a firm soil. The response quantity of interest is displacement of the top story of the structure. For the numerical study, the MTMFD is assumed to be attached to the top story of the structure as shown in Fig. 1.

The mass of each floor is taken as $10,000 \mathrm{~kg}$. The natural frequencies of the structure are calculated as 2, 5.838, 9.203, 11.822, $13.484 \mathrm{~Hz}$. For the present study, the results are obtained with the interval, $\Delta t=0.02,0.01$ and 0.005 , respectively. The number of iteration in each time step is taken as $50-200$ to determine the incremental frictional 


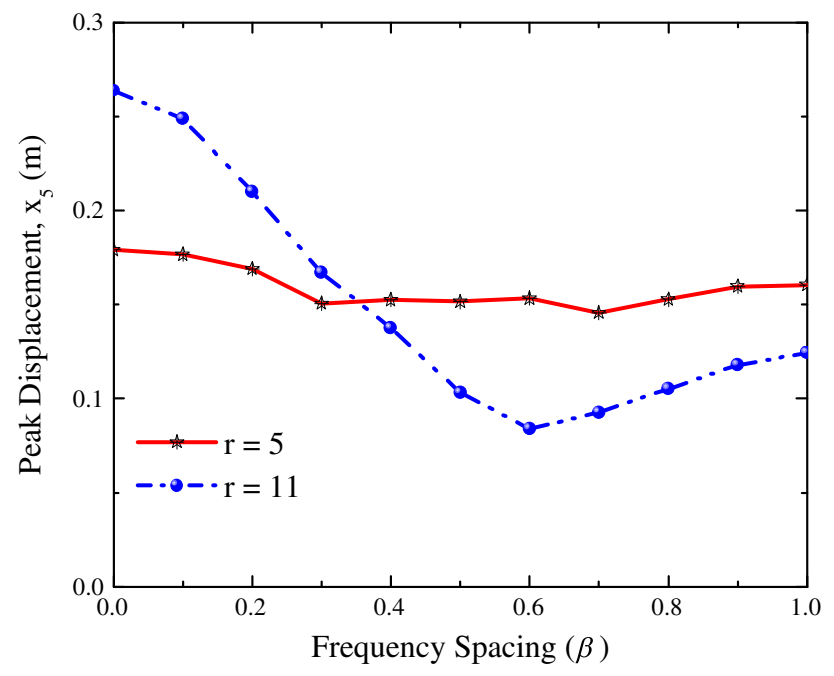

Fig. 5 Variation of peak displacement of top story with frequency spacing

force of the MTMFD. The important parameters on which the efficiency of MTMFD depends such as mass ratio, tuning ratio, frequency spacing, damper slip force, number of TMFD units in MTMFD are discussed here. To investigate the effectiveness of the MTMFD over a STMFD, the response of the system with MTMFD is compared with the response of uncontrolled and controlled system with STMFD, respectively.

\section{Effect of mass ratio}

The effect of mass ratio on the performance of the MTMFD is studied in Fig. 3 by plotting the peak displacement of the top story against the mass ratio for different number of TMFD units. The mass ratio is varied from 0.01 to 0.1 , which shows the total mass of MTMFD is varying from 1 to $10 \%$ of the total mass of the main structure. It is observed that the response of the structure decreases with the increase in mass ratio. In general, a higher mass ratio is beneficial for vibration control, but due to practical limitations the acceptable value of mass ratio is $10-15 \%$ only. It is also observed that the value of response reduction with respect to mass ratio varies with the number of TMFD unit in MTMFD. Thus, the higher mass ratio is beneficial for more response reduction of a structure using MTMFD.

\section{Effect of tuning ratio}

Figure 4 shows variation of peak top floor displacement of structure against tuning ratio, $f$, for different numbers of TMFD. The fundamental time period of the primary structure is kept constant, while the average time period

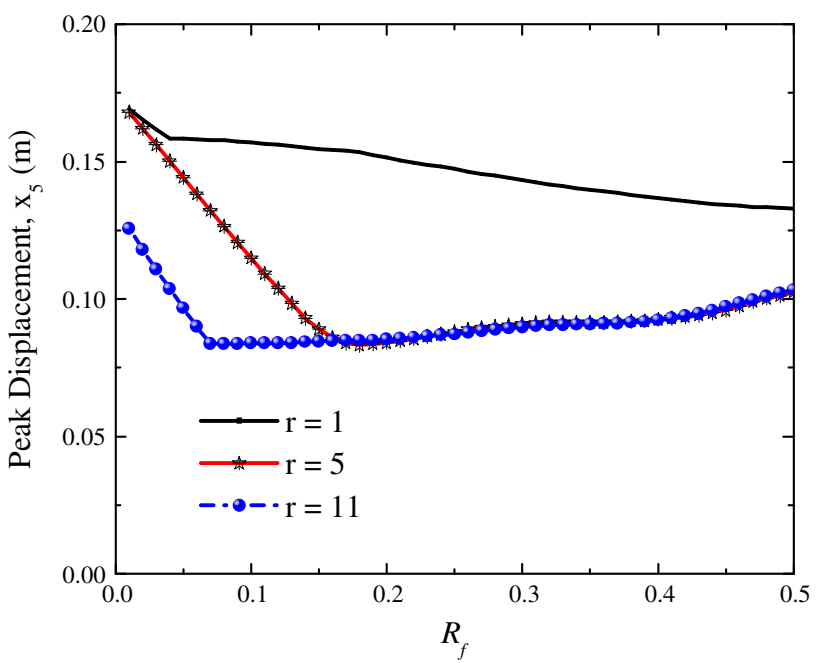

Fig. 6 Variation of peak displacement of top story with Rf

(i.e., average frequency) of TMFD is changed in such a way that the $f$ varies from 0.1 to 1.8 . It is noted from the figure that there is a reduction in the response of interest with the increasing tuning ratio up to certain value and after that it increases the response. It shows that an optimum value of tuning ratio exists at which the response of the system reduced to maximum value. It is also observed that an optimum value of tuning ratio varies with the number of TMFD units. Thus, an optimum value of tuning frequency ratio exists at which the response of the system reduces to minimum value.

\section{Effect of frequency spacing}

Figure 5 shows the effect of frequency spacing on the performance of MTMFD. The frequency spacing is varied from 0.1 to 1.0 , and optimum value of mass ratio and tuning ratio is considered with respect to the number of TMFD units in MTMFD. It is observed from the Fig. 5 that the displacement response of the structure decreases with the increase in frequency spacing up to a certain value and after that it gradually increases. Thus, an optimum value of frequency spacing exists for which the reduction of response by MTMFD is maximum.

\section{Effect of friction force}

To investigate the effect of damper friction force, the variation of peak displacement of top story is plotted with respect to varying values of normalized friction force, $R_{f}$ in Fig. 6. It is observed from the Fig. 6 that the response decreases with the increase in value of $R_{f}$ up to certain point and after that it tends to be constant. It is also 
Table 2 Optimum parameters of TMFD and MTMFD for Imperial Valley (1940) earthquake

\begin{tabular}{|c|c|c|c|c|}
\hline Mass ratio & No. of TMFD $(r)$ & $r=1$ & $r=5$ & $r=11$ \\
\hline \multirow[t]{5}{*}{0.01} & $\beta^{\text {opt }}$ & - & 0.1 & 0.1 \\
\hline & $f^{\text {opt }}$ & 0.9 & 0.8 & 0.8 \\
\hline & $R_{\mathrm{f}}^{\mathrm{opt}}$ & 0.01 & 0.01 & 0.01 \\
\hline & Peak displacement response (m) & 0.0533 & 0.0542 & 0.0542 \\
\hline & Percentage reduction $(\%)$ & 11.02 & 9.60 & 9.62 \\
\hline \multirow[t]{5}{*}{0.02} & $\beta^{\mathrm{opt}}$ & - & 0.1 & 0.1 \\
\hline & $f^{\mathrm{opt}}$ & 0.7 & 0.7 & 0.7 \\
\hline & $R_{\mathrm{f}}^{\mathrm{opt}}$ & 0.01 & 0.01 & 0.01 \\
\hline & Peak displacement response (m) & 0.0519 & 0.0520 & 0.0520 \\
\hline & Percentage reduction $(\%)$ & 13.36 & 13.24 & 13.29 \\
\hline \multirow[t]{5}{*}{0.03} & $\beta^{\mathrm{opt}}$ & - & 0.4 & 0.5 \\
\hline & $f^{\text {opt }}$ & 0.7 & 0.9 & 0.9 \\
\hline & $R_{\mathrm{f}}^{\mathrm{opt}}$ & 0.01 & 0.02 & 0.01 \\
\hline & Peak displacement response (m) & 0.0519 & 0.0508 & 0.0517 \\
\hline & Percentage reduction $(\%)$ & 13.35 & 15.26 & 13.82 \\
\hline \multirow[t]{5}{*}{0.04} & $\beta^{\mathrm{opt}}$ & - & 0.4 & 0.4 \\
\hline & $f^{\text {opt }}$ & 0.6 & 0.9 & 0.9 \\
\hline & $R_{f}^{o p t}$ & 0.04 & 0.02 & 0.01 \\
\hline & Peak displacement response (m) & 0.0504 & 0.0497 & 0.0490 \\
\hline & Percentage reduction $(\%)$ & 15.93 & 17.05 & 18.29 \\
\hline \multirow[t]{5}{*}{0.05} & $\beta^{\text {opt }}$ & - & 0.4 & 0.4 \\
\hline & $f^{\text {opt }}$ & 0.6 & 0.9 & 0.9 \\
\hline & $R_{\mathrm{f}}^{\mathrm{opt}}$ & 0.02 & 0.02 & 0.01 \\
\hline & Peak displacement response (m) & 0.0495 & 0.0489 & 0.0480 \\
\hline & Percentage reduction $(\%)$ & 17.38 & 18.41 & 19.84 \\
\hline \multirow[t]{5}{*}{0.06} & $\beta^{\text {opt }}$ & - & 0.7 & 0.4 \\
\hline & $f^{o p t}$ & 0.6 & 0.8 & 0.9 \\
\hline & $R_{f}^{o p t}$ & 0.04 & 0.02 & 0.01 \\
\hline & Peak displacement response (m) & 0.0504 & 0.0477 & 0.0472 \\
\hline & Percentage reduction $(\%)$ & 15.89 & 20.40 & 21.32 \\
\hline \multirow[t]{5}{*}{0.07} & $\beta^{\mathrm{opt}}$ & - & 0.7 & 0.4 \\
\hline & $f^{\text {opt }}$ & 0.9 & 0.8 & 0.9 \\
\hline & $R_{\mathrm{f}}^{\mathrm{opt}}$ & 0.06 & 0.01 & 0.01 \\
\hline & Peak displacement response (m) & 0.0504 & 0.0461 & 0.0463 \\
\hline & Percentage reduction $(\%)$ & 15.88 & 23.01 & 22.69 \\
\hline \multirow[t]{5}{*}{0.08} & $\beta^{\mathrm{opt}}$ & - & 0.7 & 0.7 \\
\hline & $f^{\text {opt }}$ & 0.9 & 0.8 & 0.8 \\
\hline & $R_{\mathrm{f}}^{\mathrm{opt}}$ & 0.05 & 0.01 & 0.02 \\
\hline & Peak displacement response (m) & 0.0494 & 0.0452 & 0.0453 \\
\hline & Percentage reduction (\%) & 17.62 & 24.59 & 24.39 \\
\hline \multirow[t]{5}{*}{0.09} & $\beta^{\mathrm{opt}}$ & - & 0.7 & 0.7 \\
\hline & $f^{\mathrm{opt}}$ & 0.9 & 0.8 & 0.8 \\
\hline & $R_{\mathrm{f}}^{\mathrm{opt}}$ & 0.05 & 0.01 & 0.01 \\
\hline & Peak displacement response (m) & 0.0490 & 0.0444 & 0.0437 \\
\hline & Percentage reduction $(\%)$ & 18.24 & 25.97 & 27.05 \\
\hline
\end{tabular}


Table 2 continued

\begin{tabular}{|c|c|c|c|c|}
\hline Mass ratio & No. of TMFD $(r)$ & $r=1$ & $r=5$ & $r=11$ \\
\hline \multirow[t]{5}{*}{0.1} & $\beta^{\text {opt }}$ & - & 0.7 & 0.7 \\
\hline & $f^{\mathrm{opt}}$ & 0.9 & 0.8 & 0.8 \\
\hline & $R_{\mathrm{f}}^{\mathrm{opt}}$ & 0.06 & 0.01 & 0.01 \\
\hline & Peak displacement response $(\mathrm{m})$ & 0.0495 & 0.0436 & 0.0429 \\
\hline & Percentage reduction (\%) & 17.42 & 27.30 & 28.45 \\
\hline
\end{tabular}

Table 3 Optimum parameters of TMFD and MTMFD for Loma Prieta (1989) earthquake

\begin{tabular}{|c|c|c|c|c|}
\hline Mass ratio & No. of TMFD $(r)$ & $r=1$ & $r=5$ & $r=11$ \\
\hline \multirow[t]{5}{*}{0.01} & $\beta^{\text {opt }}$ & - & 0.8 & 0.1 \\
\hline & $f^{\text {opt }}$ & 1 & 0.9 & 1 \\
\hline & $R_{\mathrm{f}}^{\mathrm{opt}}$ & 0.18 & 0.18 & 0.07 \\
\hline & Peak displacement response (m) & 0.1495 & 0.1612 & 0.1293 \\
\hline & Percentage reduction $(\%)$ & 13.98 & 7.22 & 25.56 \\
\hline \multirow[t]{5}{*}{0.02} & $\beta^{\text {opt }}$ & - & 0.7 & 0.3 \\
\hline & $f^{\text {opt }}$ & 1 & 0.9 & 1 \\
\hline & $R_{\mathrm{f}}^{\mathrm{opt}}$ & 0.2 & 0.11 & 0.07 \\
\hline & Peak displacement response (m) & 0.1629 & 0.1392 & 0.1461 \\
\hline & Percentage reduction $(\%)$ & 6.24 & 19.88 & 15.89 \\
\hline \multirow[t]{5}{*}{0.03} & $\beta^{\text {opt }}$ & - & 0.3 & 0.3 \\
\hline & $f^{\text {opt }}$ & 1 & 0.9 & 0.9 \\
\hline & $R_{\mathrm{f}}^{\mathrm{opt}}$ & 0.2 & 0.11 & 0.08 \\
\hline & Peak displacement response (m) & 0.1467 & 0.1264 & 0.1296 \\
\hline & Percentage reduction $(\%)$ & 15.53 & 27.23 & 25.43 \\
\hline \multirow[t]{5}{*}{0.04} & $\beta^{\text {opt }}$ & - & 0.4 & 0.4 \\
\hline & $f^{\text {opt }}$ & 1 & 0.9 & 0.9 \\
\hline & $R_{\mathrm{f}}^{\mathrm{opt}}$ & 0.2 & 0.17 & 0.09 \\
\hline & Peak displacement response $(\mathrm{m})$ & 0.1281 & 0.1204 & 0.1195 \\
\hline & Percentage reduction $(\%)$ & 26.27 & 30.73 & 31.21 \\
\hline \multirow[t]{5}{*}{0.05} & $\beta^{\text {opt }}$ & - & 0.4 & 0.5 \\
\hline & $f^{\text {opt }}$ & 1 & 0.9 & 0.9 \\
\hline & $R_{\mathrm{f}}^{\mathrm{opt}}$ & 0.2 & 0.17 & 0.09 \\
\hline & Peak displacement response $(\mathrm{m})$ & 0.1426 & 0.1139 & 0.1045 \\
\hline & Percentage reduction $(\%)$ & 17.93 & 34.41 & 39.84 \\
\hline \multirow[t]{5}{*}{0.06} & $\beta^{\text {opt }}$ & - & 0.5 & 0.5 \\
\hline & $f^{\text {opt }}$ & 1 & 0.9 & 0.9 \\
\hline & $R_{\mathrm{f}}^{\mathrm{opt}}$ & 0.2 & 0.16 & 0.09 \\
\hline & Peak displacement response (m) & 0.1574 & 0.1068 & 0.0990 \\
\hline & Percentage reduction $(\%)$ & 9.40 & 38.52 & 43.03 \\
\hline \multirow[t]{5}{*}{0.07} & $\beta^{\text {opt }}$ & - & 0.5 & 0.6 \\
\hline & $f^{\text {opt }}$ & 0.8 & 0.9 & 0.9 \\
\hline & $R_{\mathrm{f}}^{\mathrm{opt}}$ & 0.2 & 0.16 & 0.08 \\
\hline & Peak displacement response $(\mathrm{m})$ & 0.1545 & 0.0959 & 0.0959 \\
\hline & Percentage reduction $(\%)$ & 11.07 & 44.78 & 44.82 \\
\hline
\end{tabular}


Table 3 continued

\begin{tabular}{|c|c|c|c|c|}
\hline Mass ratio & No. of TMFD $(r)$ & $r=1$ & $r=5$ & $r=11$ \\
\hline \multirow[t]{5}{*}{0.08} & $\beta^{\mathrm{opt}}$ & - & 0.5 & 0.6 \\
\hline & $f^{\text {opt }}$ & 0.6 & 0.9 & 0.9 \\
\hline & $R_{\mathrm{f}}^{\mathrm{opt}}$ & 0.2 & 0.16 & 0.08 \\
\hline & Peak displacement response (m) & 0.1552 & 0.0875 & 0.0888 \\
\hline & Percentage reduction $(\%)$ & 10.66 & 49.61 & 48.89 \\
\hline \multirow[t]{5}{*}{0.09} & $\beta^{\mathrm{opt}}$ & - & 0.5 & 0.6 \\
\hline & $f^{\mathrm{opt}}$ & 0.6 & 0.9 & 0.9 \\
\hline & $R_{\mathrm{f}}^{\mathrm{opt}}$ & 0.2 & 0.18 & 0.1 \\
\hline & Peak displacement response (m) & 0.1515 & 0.0833 & 0.0840 \\
\hline & Percentage reduction $(\%)$ & 12.81 & 52.08 & 51.68 \\
\hline \multirow[t]{5}{*}{0.1} & $\beta^{\text {opt }}$ & - & 0.5 & 0.6 \\
\hline & $f^{\text {opt }}$ & 0.6 & 0.9 & 0.9 \\
\hline & $R_{\mathrm{f}}^{\mathrm{opt}}$ & 0.2 & 0.19 & 0.11 \\
\hline & Peak displacement response $(\mathrm{m})$ & 0.1475 & 0.0843 & 0.0812 \\
\hline & Percentage reduction $(\%)$ & 15.11 & 51.45 & 53.29 \\
\hline
\end{tabular}

Table 4 Optimum parameters of TMFD and MTMFD for Landers (1992) earthquake

\begin{tabular}{|c|c|c|c|c|}
\hline Mass ratio & No. of TMFD $(r)$ & $r=1$ & $r=5$ & $r=11$ \\
\hline \multirow[t]{5}{*}{0.01} & $\beta^{\text {opt }}$ & - & 0.2 & 0.2 \\
\hline & $f^{\text {opt }}$ & 1 & 0.9 & 0.9 \\
\hline & $R_{\mathrm{f}}^{\mathrm{opt}}$ & 0.06 & 0.01 & 0.01 \\
\hline & Peak displacement response (m) & 0.0391 & 0.0386 & 0.0396 \\
\hline & Percentage reduction $(\%)$ & 27.94 & 28.97 & 27.14 \\
\hline \multirow[t]{5}{*}{0.02} & $\beta^{\text {opt }}$ & - & 0.1 & 0.5 \\
\hline & $f^{\text {opt }}$ & 1 & 0.9 & 0.8 \\
\hline & $R_{\mathrm{f}}^{\mathrm{opt}}$ & 0.08 & 0.01 & 0.01 \\
\hline & Peak displacement response (m) & 0.0393 & 0.0400 & 0.0398 \\
\hline & Percentage reduction $(\%)$ & 27.59 & 26.32 & 26.69 \\
\hline \multirow[t]{5}{*}{0.03} & $\beta^{\text {opt }}$ & - & 0.9 & 0.8 \\
\hline & $f^{\text {opt }}$ & 1 & 0.8 & 0.7 \\
\hline & $R_{\mathrm{f}}^{\mathrm{opt}}$ & 0.08 & 0.02 & 0.01 \\
\hline & Peak displacement response (m) & 0.0417 & 0.0397 & 0.0408 \\
\hline & Percentage reduction $(\%)$ & 23.15 & 26.87 & 24.82 \\
\hline \multirow[t]{5}{*}{0.04} & $\beta^{\text {opt }}$ & - & 0.8 & 0.8 \\
\hline & $f^{\text {opt }}$ & 1 & 0.7 & 0.7 \\
\hline & $R_{\mathrm{f}}^{\mathrm{opt}}$ & 0.09 & 0.01 & 0.01 \\
\hline & Peak displacement response (m) & 0.0439 & 0.0391 & 0.0392 \\
\hline & Percentage reduction $(\%)$ & 19.12 & 28.06 & 27.73 \\
\hline \multirow[t]{5}{*}{0.05} & $\beta^{\text {opt }}$ & - & 0.8 & 0.8 \\
\hline & $f^{\text {opt }}$ & 0.6 & 0.7 & 0.7 \\
\hline & $R_{\mathrm{f}}^{\mathrm{opt}}$ & 0.03 & 0.01 & 0.01 \\
\hline & Peak displacement response (m) & 0.0423 & 0.0404 & 0.0396 \\
\hline & Percentage reduction $(\%)$ & 22.10 & 25.56 & 27.09 \\
\hline
\end{tabular}


Table 4 continued

\begin{tabular}{|c|c|c|c|c|}
\hline Mass ratio & No. of TMFD $(r)$ & $r=1$ & $r=5$ & $r=11$ \\
\hline \multirow[t]{5}{*}{0.06} & $\beta^{\text {opt }}$ & - & 0.8 & 0.2 \\
\hline & $f^{\text {opt }}$ & 0.6 & 0.7 & 0.6 \\
\hline & $R_{\mathrm{f}}^{\mathrm{opt}}$ & 0.03 & 0.02 & 0.01 \\
\hline & Peak displacement response (m) & 0.0408 & 0.0394 & 0.0402 \\
\hline & Percentage reduction $(\%)$ & 24.82 & 27.42 & 26.01 \\
\hline \multirow[t]{5}{*}{0.07} & $\beta^{\text {opt }}$ & - & 0.2 & 0.2 \\
\hline & $f^{\text {opt }}$ & 0.6 & 0.6 & 0.6 \\
\hline & $R_{\mathrm{f}}^{\mathrm{opt}}$ & 0.03 & 0.01 & 0.02 \\
\hline & Peak displacement response (m) & 0.0399 & 0.0393 & 0.0396 \\
\hline & Percentage reduction $(\%)$ & 26.58 & 27.56 & 27.07 \\
\hline \multirow[t]{5}{*}{0.08} & $\beta^{\text {opt }}$ & - & 0.2 & 0.2 \\
\hline & $f^{\text {opt }}$ & 0.6 & 0.6 & 0.6 \\
\hline & $R_{\mathrm{f}}^{\mathrm{opt}}$ & 0.02 & 0.01 & 0.02 \\
\hline & Peak displacement response (m) & 0.0394 & 0.0391 & 0.0392 \\
\hline & Percentage reduction $(\%)$ & 27.42 & 27.97 & 27.71 \\
\hline \multirow[t]{5}{*}{0.09} & $\beta^{\text {opt }}$ & - & 0.1 & 0.1 \\
\hline & $f^{\text {opt }}$ & 0.6 & 0.6 & 0.6 \\
\hline & $R_{\mathrm{f}}^{\mathrm{opt}}$ & 0.02 & 0.02 & 0.02 \\
\hline & Peak displacement response (m) & 0.0383 & 0.0387 & 0.0386 \\
\hline & Percentage reduction $(\%)$ & 29.37 & 28.66 & 28.82 \\
\hline \multirow[t]{5}{*}{0.1} & $\beta^{\text {opt }}$ & - & 0.1 & 0.1 \\
\hline & $f^{\text {opt }}$ & 0.6 & 0.6 & 0.6 \\
\hline & $R_{\mathrm{f}}^{\mathrm{opt}}$ & 0.02 & 0.02 & 0.06 \\
\hline & Peak displacement response (m) & 0.0391 & 0.0379 & 0.0376 \\
\hline & Percentage reduction $(\%)$ & 27.93 & 30.24 & 30.75 \\
\hline
\end{tabular}

Table 5 Optimum parameters of TMFD and MTMFD for Kobe (1995) earthquake

\begin{tabular}{|c|c|c|c|c|}
\hline Mass ratio & No. of TMFD $(r)$ & $r=1$ & $r=5$ & $r=11$ \\
\hline \multirow[t]{5}{*}{0.01} & $\beta^{\text {opt }}$ & - & 0.1 & 0.1 \\
\hline & $f^{\mathrm{opt}}$ & 0.9 & 1 & 1 \\
\hline & $R_{\mathrm{f}}^{\mathrm{opt}}$ & 0.2 & 0.07 & 0.09 \\
\hline & Peak displacement response $(\mathrm{m})$ & 0.1871 & 0.1628 & 0.1631 \\
\hline & Percentage reduction $(\%)$ & 13.82 & 25.05 & 24.89 \\
\hline \multirow[t]{5}{*}{0.02} & $\beta^{\text {opt }}$ & - & 0.2 & 0.2 \\
\hline & $f^{\mathrm{opt}}$ & 1 & 1 & 1 \\
\hline & $R_{\mathrm{f}}^{\mathrm{opt}}$ & 0.2 & 0.07 & 0.07 \\
\hline & Peak displacement response (m) & 0.2004 & 0.1348 & 0.1324 \\
\hline & Percentage reduction $(\%)$ & 7.71 & 37.92 & 39.01 \\
\hline \multirow[t]{5}{*}{0.03} & $\beta^{\mathrm{opt}}$ & - & 0.2 & 0.3 \\
\hline & $f^{\text {opt }}$ & 1 & 1 & 1 \\
\hline & $R_{\mathrm{f}}^{\mathrm{opt}}$ & 0.2 & 0.08 & 0.02 \\
\hline & Peak displacement response (m) & 0.1824 & 0.1174 & 0.1207 \\
\hline & Percentage reduction $(\%)$ & 16.02 & 45.94 & 44.43 \\
\hline
\end{tabular}


Table 5 continued

\begin{tabular}{|c|c|c|c|c|}
\hline Mass ratio & No. of TMFD $(r)$ & $r=1$ & $r=5$ & $r=11$ \\
\hline \multirow[t]{5}{*}{0.04} & $\beta^{\text {opt }}$ & - & 0.2 & 0.3 \\
\hline & $f^{\text {opt }}$ & 1 & 1 & 1 \\
\hline & $R_{\mathrm{f}}^{\mathrm{opt}}$ & 0.2 & 0.08 & 0.01 \\
\hline & Peak displacement response (m) & 0.1573 & 0.1059 & 0.1085 \\
\hline & Percentage reduction $(\%)$ & 27.57 & 51.21 & 50.02 \\
\hline \multirow[t]{5}{*}{0.05} & $\beta^{\text {opt }}$ & - & 0.2 & 0.2 \\
\hline & $f^{\text {opt }}$ & 1 & 1 & 1 \\
\hline & $R_{\mathrm{f}}^{\mathrm{opt}}$ & 0.12 & 0.08 & 0.05 \\
\hline & Peak displacement response (m) & 0.1297 & 0.1023 & 0.1004 \\
\hline & Percentage reduction $(\%)$ & 40.25 & 52.91 & 53.77 \\
\hline \multirow[t]{5}{*}{0.06} & $\beta^{\text {opt }}$ & - & 0.2 & 0.2 \\
\hline & $f^{\text {opt }}$ & 1 & 1 & 1 \\
\hline & $R_{\mathrm{f}}^{\mathrm{opt}}$ & 0.18 & 0.09 & 0.14 \\
\hline & Peak displacement response $(\mathrm{m})$ & 0.1199 & 0.1136 & 0.1106 \\
\hline & Percentage reduction $(\%)$ & 44.79 & 47.71 & 49.05 \\
\hline \multirow[t]{5}{*}{0.07} & $\beta^{\text {opt }}$ & - & 0.5 & 0.5 \\
\hline & $f^{\text {opt }}$ & 1 & 1 & 1 \\
\hline & $R_{f}^{o p t}$ & 0.2 & 0.2 & 0.2 \\
\hline & Peak displacement response $(\mathrm{m})$ & 0.1250 & 0.1253 & 0.1176 \\
\hline & Percentage reduction $(\%)$ & 42.44 & 42.28 & 45.83 \\
\hline \multirow[t]{5}{*}{0.08} & $\beta^{\text {opt }}$ & - & 0.5 & 0.5 \\
\hline & $f^{\text {opt }}$ & 1 & 1 & 1 \\
\hline & $R_{\mathrm{f}}^{\mathrm{opt}}$ & 0.2 & 0.2 & 0.2 \\
\hline & Peak displacement response $(\mathrm{m})$ & 0.1330 & 0.1281 & 0.1153 \\
\hline & Percentage reduction $(\%)$ & 38.76 & 41.01 & 46.91 \\
\hline \multirow[t]{5}{*}{0.09} & $\beta^{\text {opt }}$ & - & 0.6 & 0.5 \\
\hline & $f^{\mathrm{opt}}$ & 1 & 1 & 1 \\
\hline & $R_{\mathrm{f}}^{\mathrm{opt}}$ & 0.2 & 0.2 & 0.2 \\
\hline & Peak displacement response $(\mathrm{m})$ & 0.1459 & 0.1289 & 0.1182 \\
\hline & Percentage reduction $(\%)$ & 32.79 & 40.62 & 45.59 \\
\hline \multirow[t]{5}{*}{0.1} & $\beta^{\text {opt }}$ & - & 0.6 & 0.5 \\
\hline & $f^{\mathrm{opt}}$ & 1 & 1 & 1 \\
\hline & $R_{\mathrm{f}}^{\mathrm{opt}}$ & 0.2 & 0.2 & 0.2 \\
\hline & Peak displacement response $(\mathrm{m})$ & 0.1568 & 0.1277 & 0.1199 \\
\hline & Percentage reduction $(\%)$ & 27.79 & 41.18 & 44.77 \\
\hline
\end{tabular}

observed from the figure that at an optimum value of $R_{f}$, the response reduction of system with MTMFD is higher than that of a STMFD. Thus, it is observed that the optimum value of $R_{f}$ exists at which the response of the system decreases significantly.

\section{Effect of number of TMFD units in MTMFD}

To study the effect of number of TMFD units in MTMFD, the number of TMFD is varied as 1, 5 and 11.
The response reduction of the structure with respect to varying parameters for different number of TMFD units is shown in Figs. 3, 4, 5 and 6. It is observed from these figures that the response reduction of structure is higher when the numbers of TMFD are 5 and 11. While in case of STMFD, the response reduction is comparatively less. It is also observed from these figures that there is a similar response reduction of MTMFD when it consists of 5 and 11 TMFD units implying that it will not be economical to increase the number of TMFD units beyond 5. Thus, after an increase in number of TMFD 

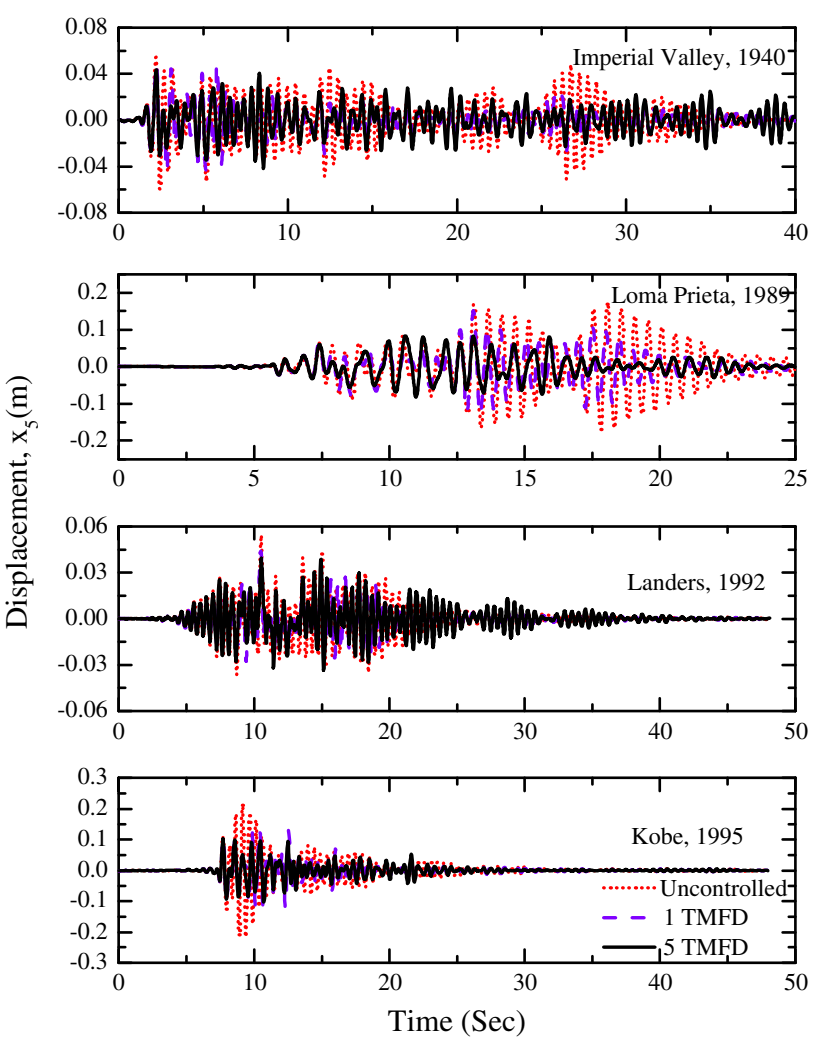

Fig. 7 Comparison of displacement response time history of top story of primary structure without TMFD with STMFD and MTMFDs

units in a MTMFD the reduction in response remains almost the same.

\section{Optimum parameters}

It is observed from the numerical study that there exists a range of optimum values of controlling parameters which influence the performance of MTMFD. In addition, the optimum values of the controlling parameter differ with the number of TMFD unit in MTMFD. To compare the effectiveness of MTMFD over the STMFD, the optimum values of important parameters and percentage respond reduction of peak displacement due to MTMFD having number of TMFD as 1, 5 and 11 are presented in Tables 2, 3,4 and 5 for different values of mass ratio for considered four earthquakes. It is observed from the tables that, in general as the value of number of TMFD units in MTMFD increases the value of optimum tuning frequency ratio and frequency spacing increases or tends to constant for higher number of TMFD units. Similarly, the value of $R_{f}$ decreases with the increasing value of TMFD units. It is also observed from the tables that with the increase in the value of mass ratio, value of optimum frequency ratio and frequency spacing decreases while the value of $R_{f}$ increases. The optimum values of parameters mentioned in these tables are used to depict the comparison of top floor displacement time history without TMFD, with STMFD and with MTMFD having same total mass, respectively in Fig. 7. It is observed from the figure that the response reduction of structure using MTMFD is more than that of STMFD having the same mass ratio. In Fig. 8, the corresponding force-deformation behavior of STMFD and MTMFD is shown. It is observed from the figure that the requirement of development of friction force for STMFD is very high in comparison to the requirement of MTMFD of same total mass, while the deformation of MTMFD is more in comparison to STMFD. Further, it also shows that the MTMFD can activate at very less friction force in comparison to STMFD. Thus, the MTMFD is more effective in controlling the response of the structure in comparison to the STMFD having the same mass ratio.

\section{Conclusions}

The response of five-story structure with STMFD and MTMFD is investigated under four different seismic excitations. The governing differential equations of motion are solved numerically, using state space method, to find out the response of the system. The parametric study is also conducted to investigate the effect of important parameters such as number of TMFD unit in MTMFD, frequency spacing, mass ratio, tuning ratio and damper slip force, on the performance of MTMFD. The optimum parameters are found out to compare the performance of structure with STMFD and MTMFD. On the basis of trends of results obtained, the following conclusions are drawn:

1. The higher mass ratio is beneficial for more response reduction of a structure using MTMFD.

2. An optimum value of tuning frequency ratio exists at which the response of the system reduces to minimum value. As the value of TMFD units in MTMFD increases the value of optimum tuning ratio increases or tend to constant for higher number of TMFD units. Also, as the value of mass ratio increases the optimum value of tuning frequency ratio decreases.

3. An optimum value of frequency spacing exists for which the reduction of response by MTMFD is maximum. As the value of TMFD units in MTMFD increases, the value of optimum frequency spacing increases or tends to constant for higher number of TMFD units. Further, with the increase of mass ratio the optimum value of frequency spacing decreases.

4. The optimum value of $R_{f}$ exists at which the response of the system decreases significantly. The optimum value of $R_{f}$ decreases with the increase in value of 

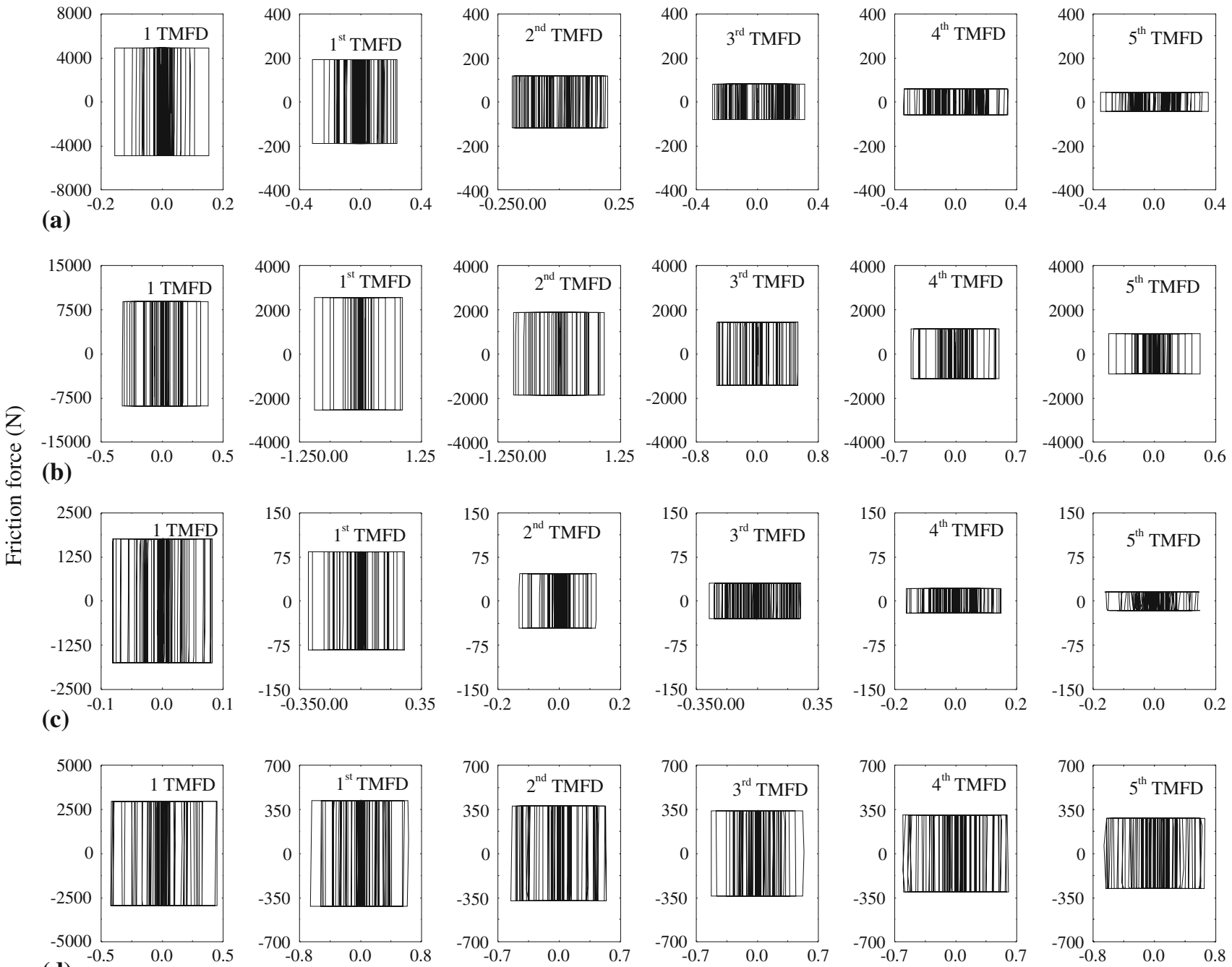

Damper Displacement (m)

Fig. 8 Hysteretic loops for STMFD and MTMFD. a Imperial Valley 1940, b Loma Prieta 1989, c Landers 1992, d Kobe 1995

TMFD units. As the value of mass ratio increases, the optimum value of $R_{f}$ increases.

5. After an increase of number of TMFD units in a MTMFD, the reduction in response remains almost the same.

6. The MTMFD is more effective in controlling the response of the system in comparison to the STMFD having the same mass ratio.

Open Access This article is distributed under the terms of the Creative Commons Attribution License which permits any use, distribution, and reproduction in any medium, provided the original author(s) and the source are credited.

\section{References}

Bhaskararao AV, Jangid RS (2006) Seismic analysis of structures connected with friction dampers. Eng Struct 28:690-703
Colajanni P, Papia M (1995) Seismic response of braced frames with and without friction dampers. Eng Struct 17:129-140

Constantinou M, Mokha A, Reinhorn A (1990) Teflon bearing in base isolation, Part II: modeling. J Struct Eng (ASCE) 116:455-474

Gewei Z, Basu B (2010) A study on friction-tuned mass damper: harmonic solution and statistical linearalization. J Vib Control 17:721-731

Joshi AS, Jangid RS (1997) Optimum parameters of multiple tuned mass dampers for base excited damped systems. J Sound Vib 202:657-667

Lee JH, Berger E, Kim JH (2005) Feasibility study of a tunable friction damper. J Sound Vib 283:707-722

Mualla IH, Belev B (2002) Performance of steel frames with a new friction damper device under earthquake excitation. Eng Struct 24:365-371

Pasquin C, Leboeuf N, Pall RT, Pall AS (2004) Friction dampers for seismic rehabilitation of Eaton's building. In: Proceeding of 13th world conference on earthquake engineering, Montreal, Paper No. 1949

Qu WL, Chen ZH, Xu YL (2001) Dynamic analysis of wind-excited truss tower with friction dampers. Comput Struct 79:2817-2831 
Ricciardelli F, Vickery BJ (1999) Tuned vibration absorbers with dry friction damping. Earthq Eng Struct Dynam 28:707-723

Wen YK (1976) Method for random vibration of hysteretic systems. J Eng Mech Div (ASCE) 102(2):249-263
Xu K, Igusa T (1992) Dynamic characteristics of multiple substructures with closely spaced frequencies. Earthq Eng Struct Dynam 21(12):1059-1070 